\title{
Global streamflow and flood response to stratospheric aerosol geoengineering
}

Liren Wei ${ }^{1}$, Duoying $\mathrm{Ji}^{1}$, Chiyuan $\mathrm{Miao}^{2}$, John C. Moore ${ }^{1,3,4}$

${ }^{1}$ College of Global Change and Earth System Science, Beijing Normal University, Beijing 100875, China

${ }^{2}$ State Key Laboratory of Earth Surface Processes and Resource Ecology, Faculty of Geographical Science, Beijing Normal University, Beijing 100875, China

${ }^{3}$ Arctic Centre, University of Lapland, P.O. Box 122, 96101 Rovaniemi, Finland

${ }^{4}$ CAS Center for Excellence in Tibetan Plateau Earth Sciences, Beijing 100101, China

\section{BNU-ESM}
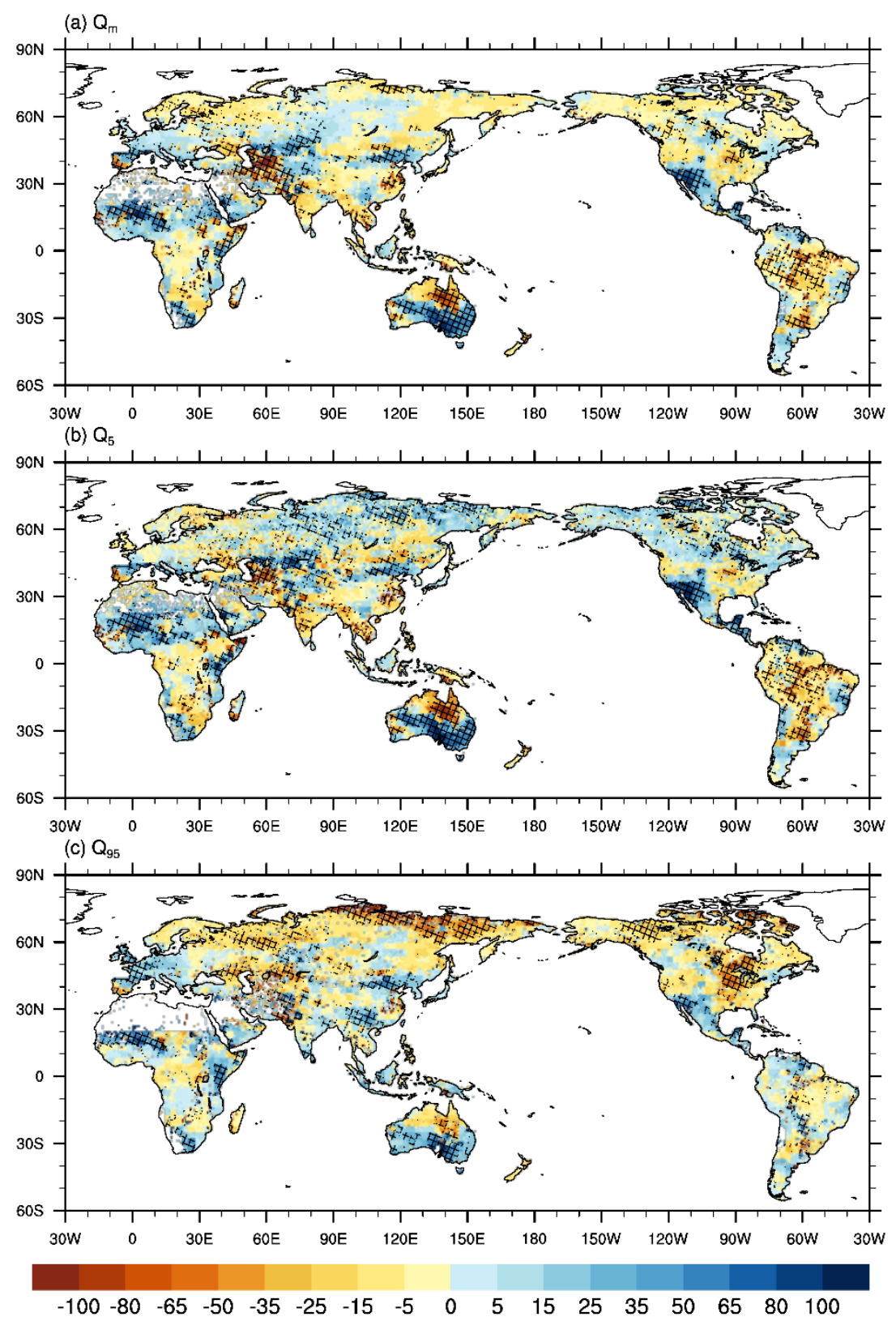
Figure S1: Relative difference of three river streamflow indicators between G4 (2030-2069) and RCP4.5 (2030-2069), as percentages of the mean of G4 and RCP4.5: $100 \% \times 2$ (G4 - RCP4.5) / (G4 + RCP4.5), projected by BNU-ESM. From Top, to bottom represents long-term mean flow $\left(\mathrm{Q}_{\mathrm{m}}\right)$; Middle, high flow $\left(\mathrm{Q}_{5}\right)$; and Bottom, low flow $\left(\mathrm{Q}_{95}\right)$. Grid cells with river discharge less than $0.01 \mathrm{~mm} /$ day are masked. Hashed areas indicate locations where the streamflow changes are significant at the $95 \%$ level.

\section{CanESM2}
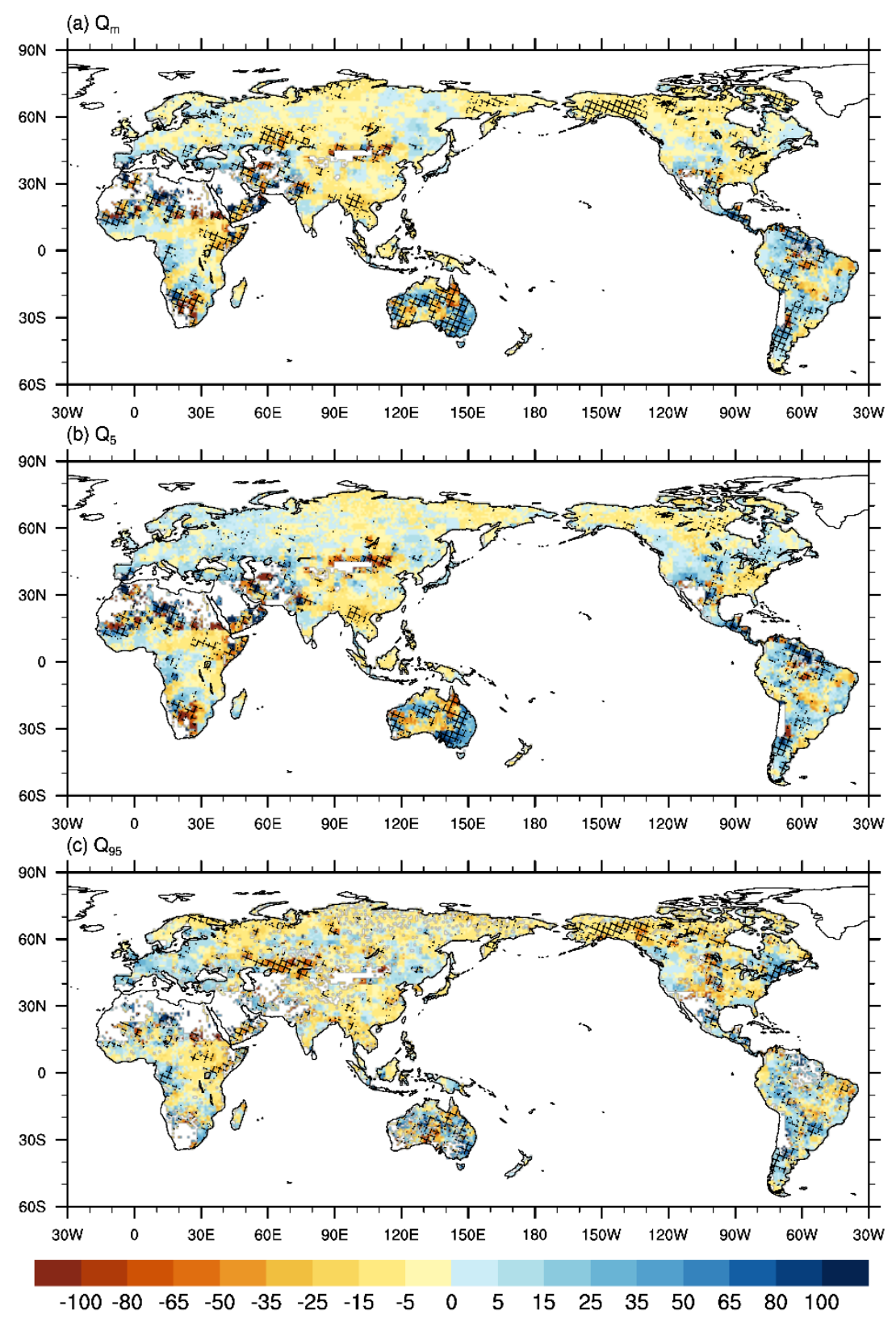

Figure S2: As for Figure S1 but for CanESM2 


\section{GEOSCCM}
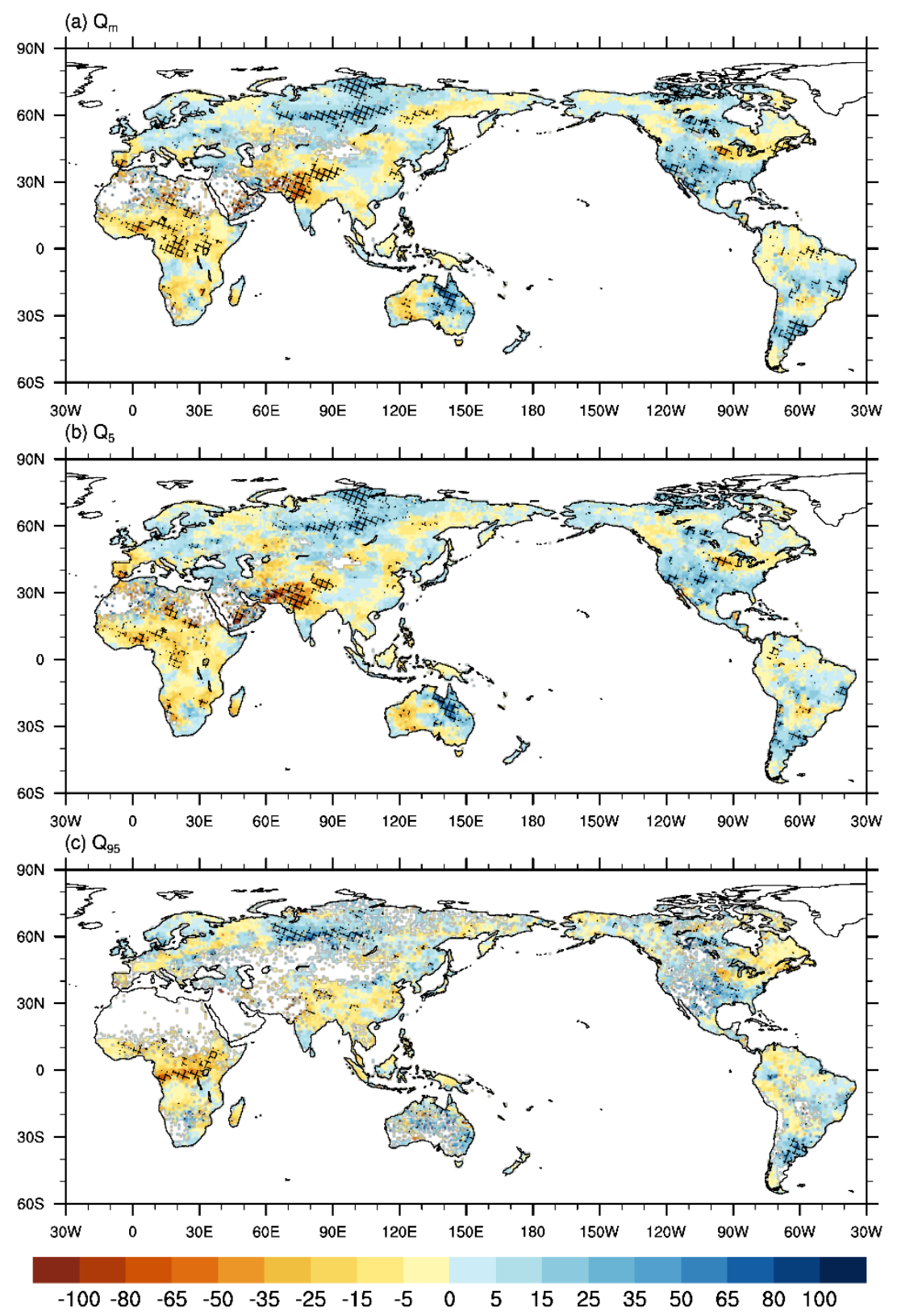

Figure S3: As for Figure S1 but for GEOSCCM. 
MIROC-ESM
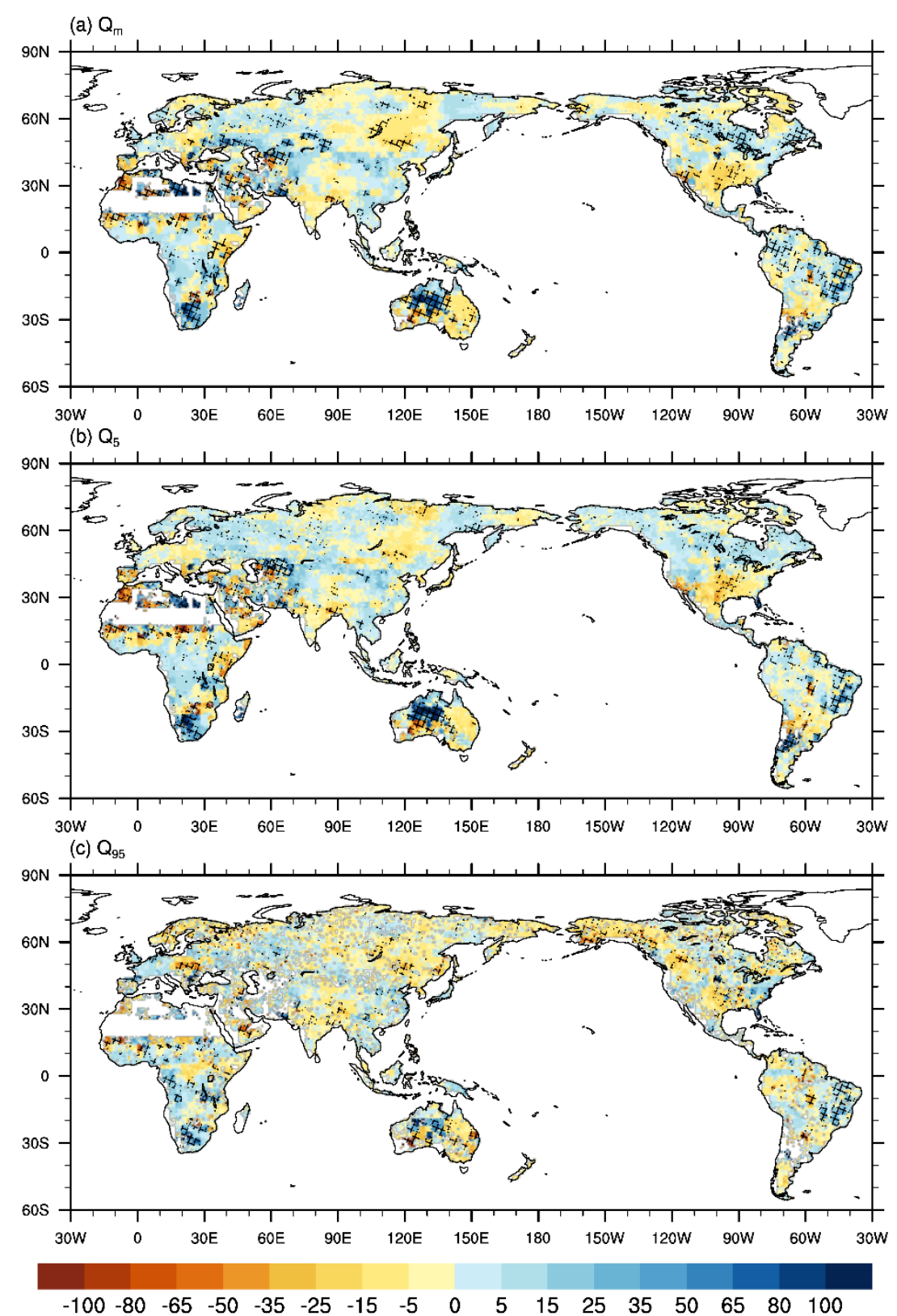

Figure S4: As for Figure S1 but for MIROC-ESM. 


\section{MIROC-ESM-CHEM}
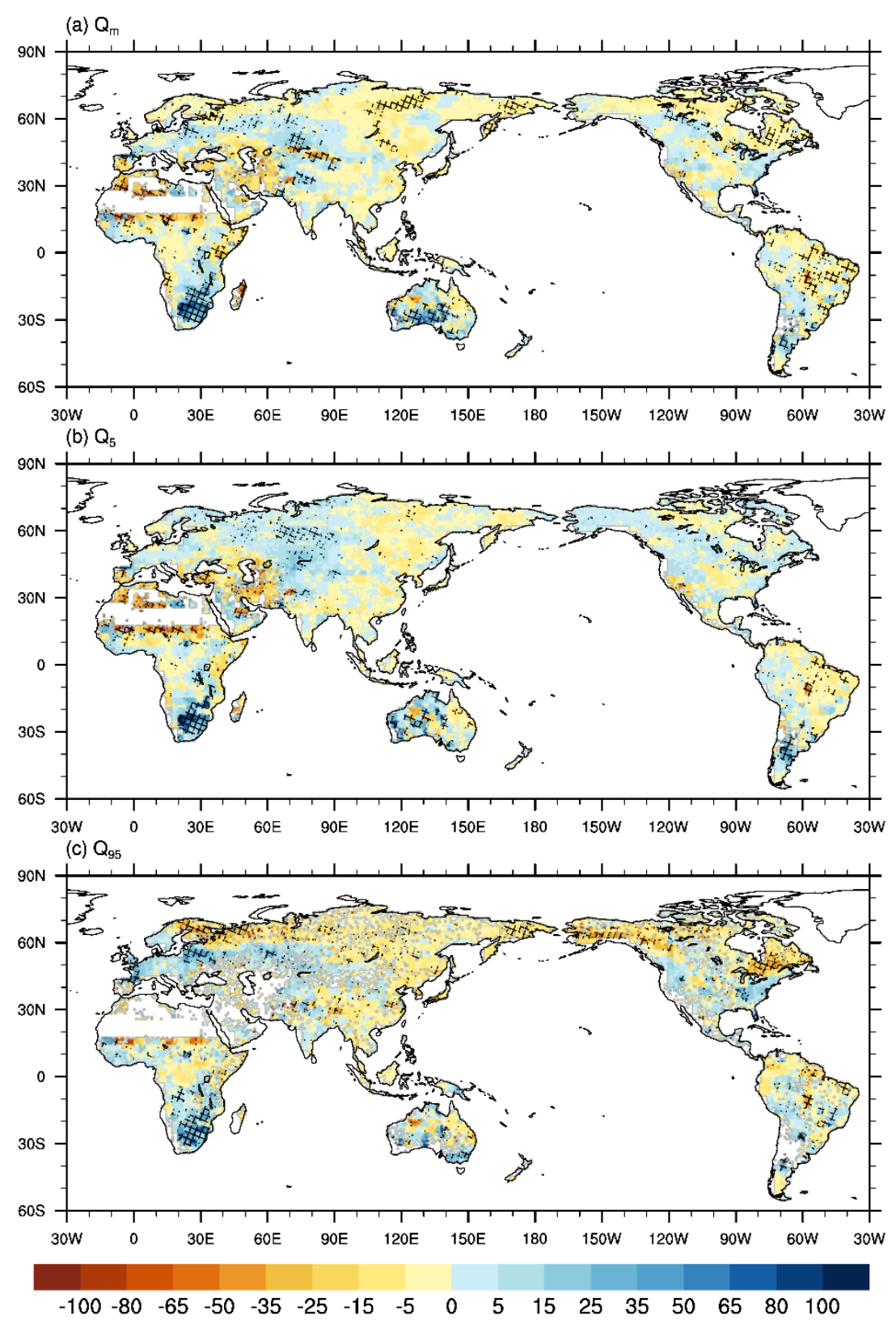

Figure S5: As for Figure S1 but for MIROC-ESM-CHEM. 


\section{NorESM1-E}
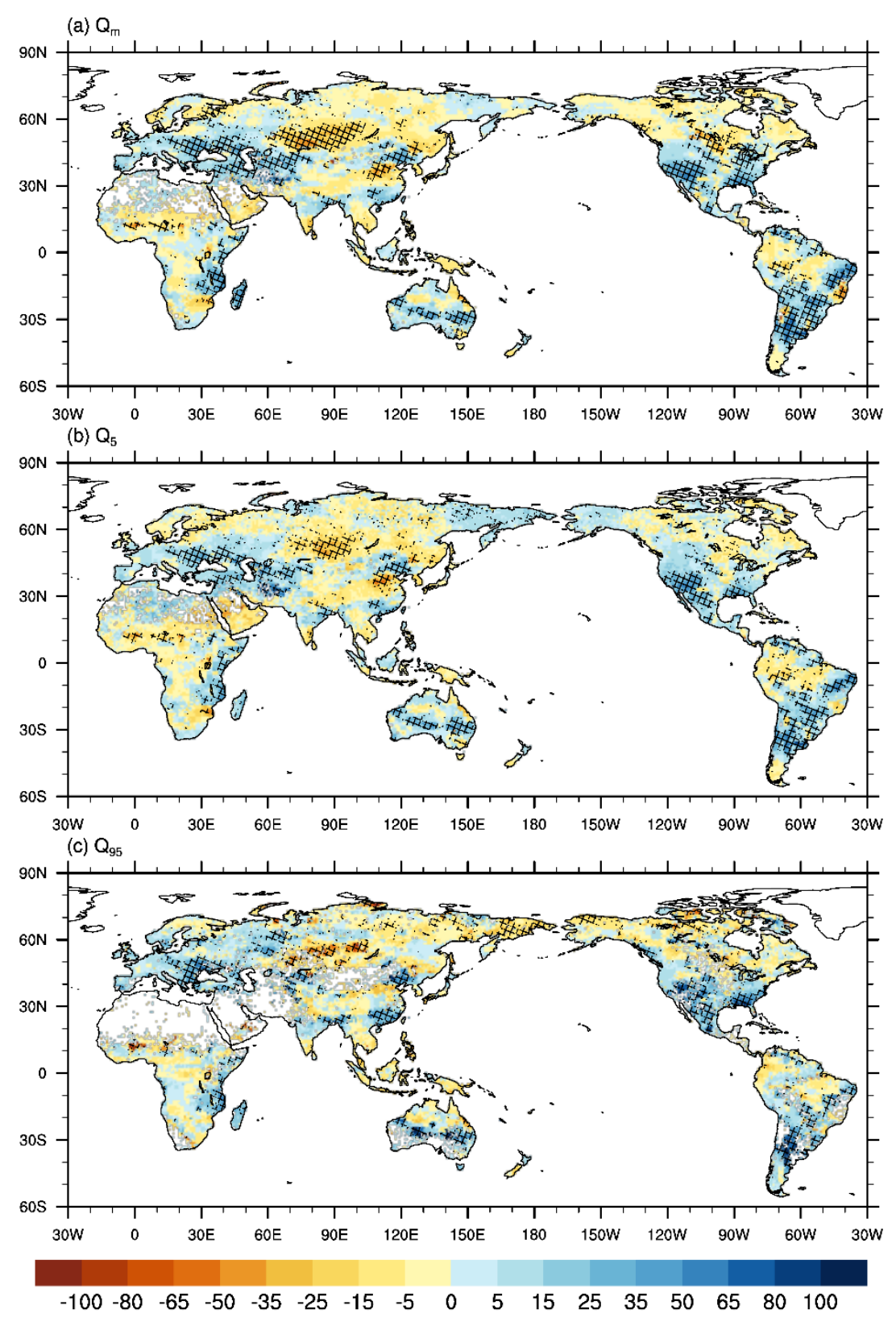

Figure S6: As for Figure S1 but for NorESM1-E. 
(a) Return Period: G4

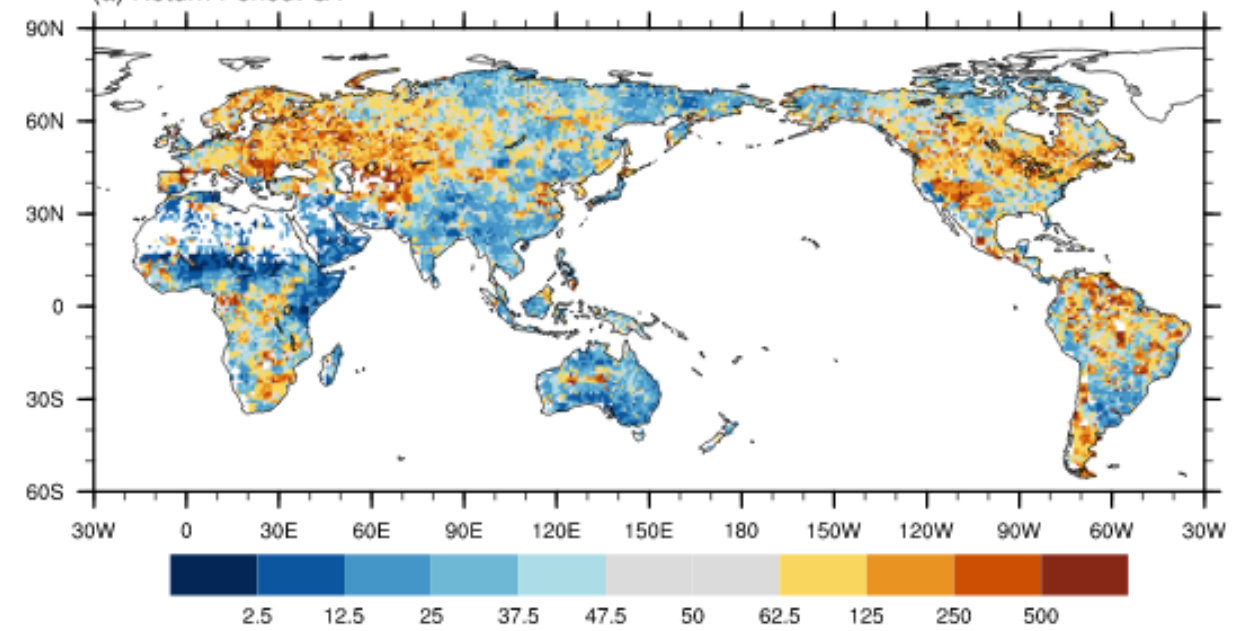

(b) Return Period: RCP4.5

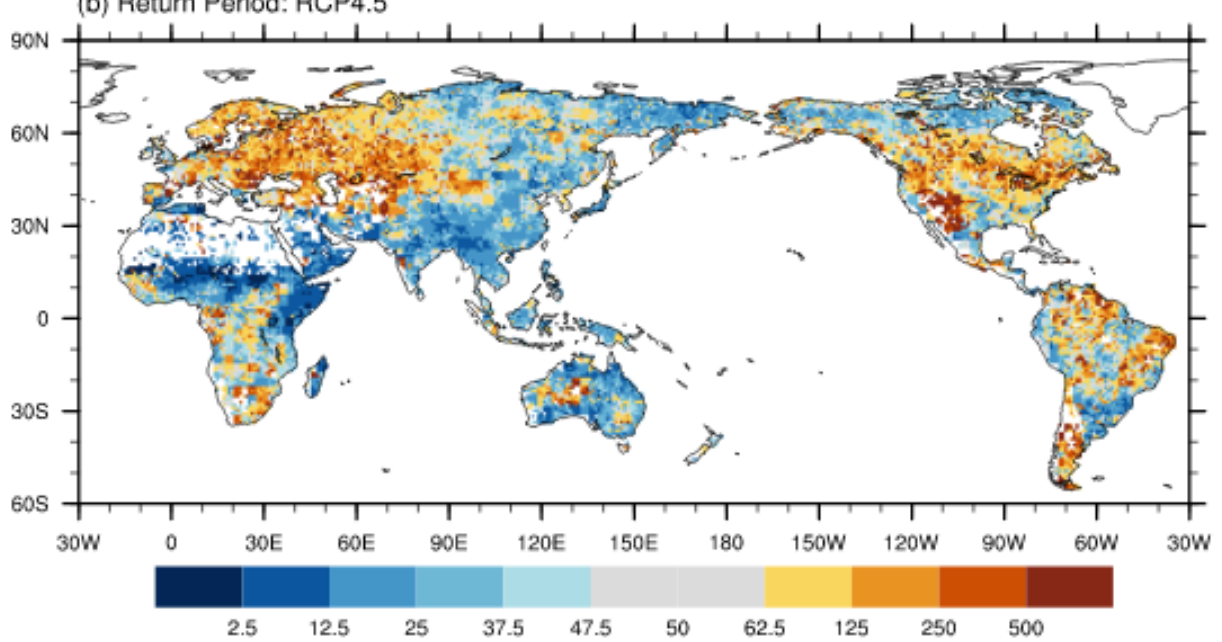

(c) Return Period: G4 - RCP4.5

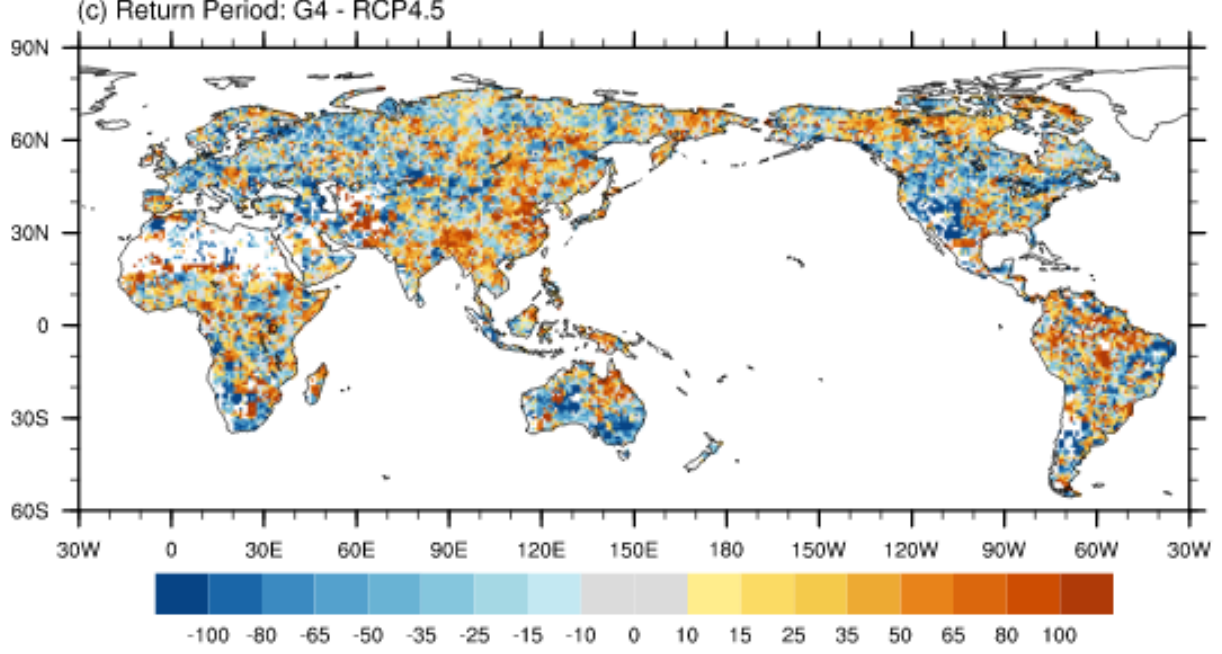

Figure S7: Multi-model ensemble median of return periods for discharge which correspond to 50year return period in the historical simulation (1960-1999) under (a) G4, (b) RCP4.5 scenarios and (c) the relative difference of $\mathrm{G} 4$ and $\mathrm{RCP} 4.5$, as percentages of mean of return periods: $100 \% \times 2(\mathrm{G} 4-\mathrm{RCP} 4.5) /(\mathrm{G} 4+\mathrm{RCP} 4.5)$. i.e. mean annual discharge for historical period less than $0.01 \mathrm{~mm} /$ day were masked out. 
(a) Return Period: G4

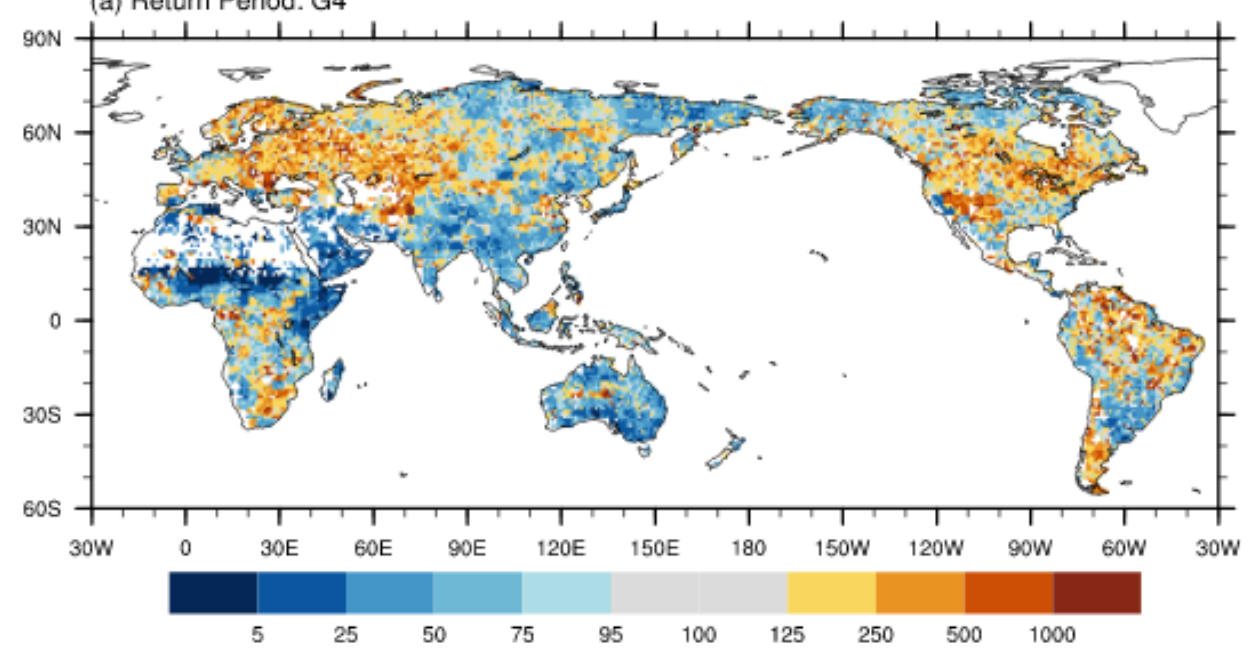

(b) Return Period: RCP4.5

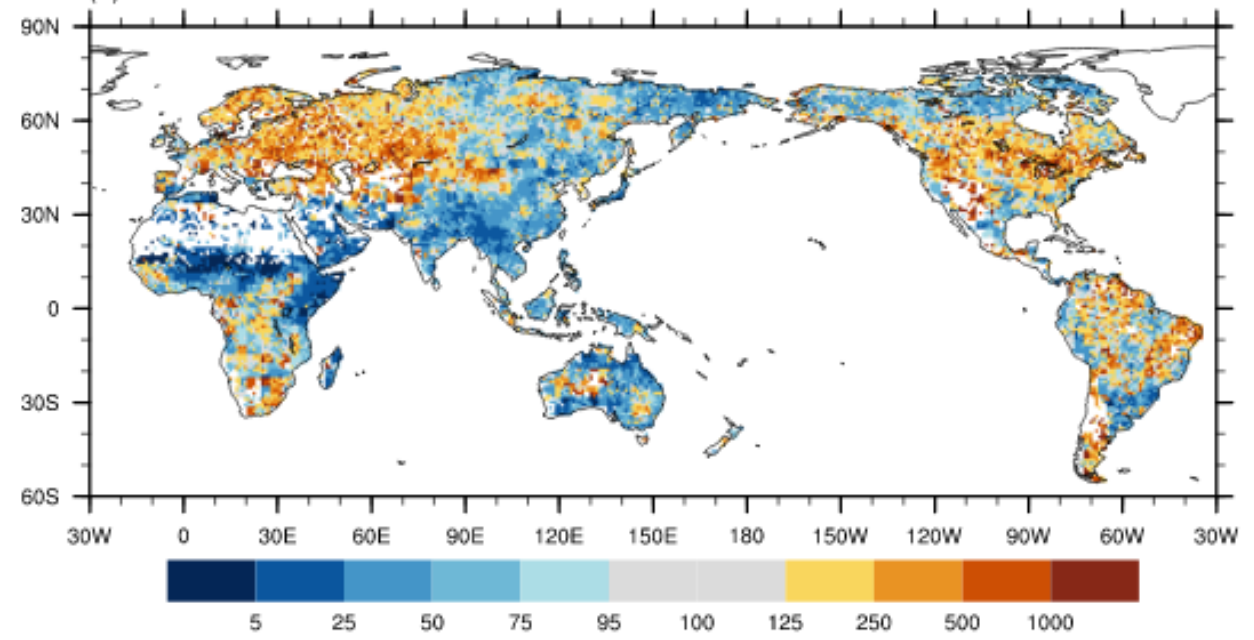

(c) Return Period: G4 - RCP4.5

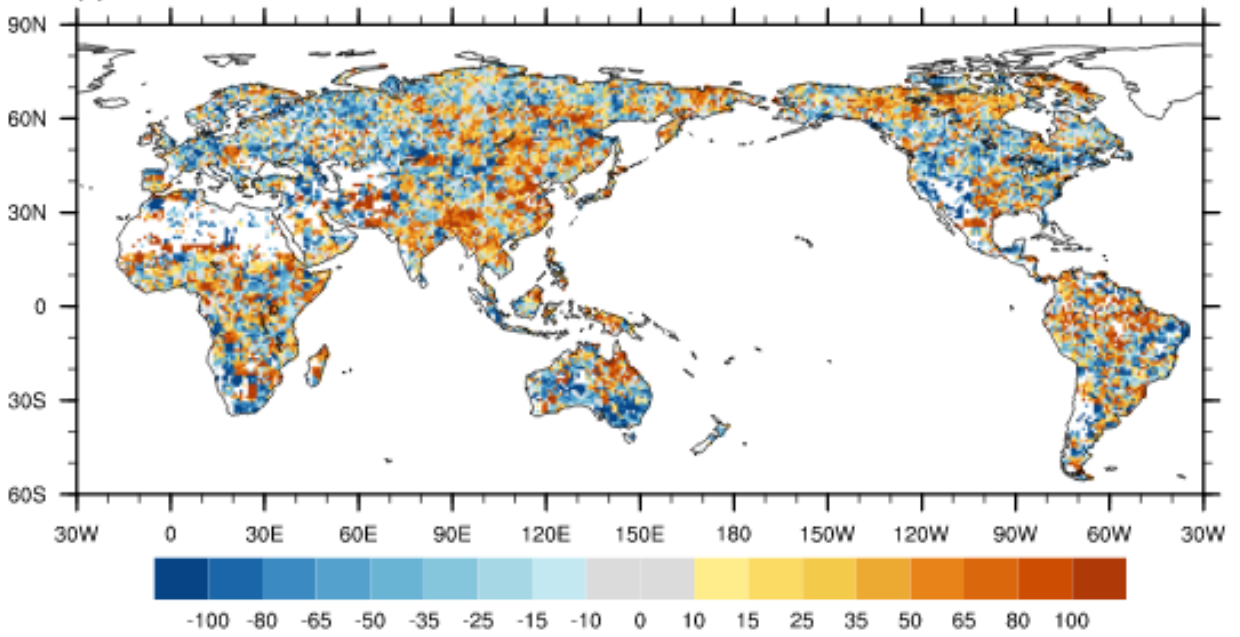

Figure S8: As for Figure S7 but for 100-year return periods. 